part of the wing. The arista of the antenna is more slender and sharper at the tip. The thoracic dorsum is dull and pollinose in the new species and shining in abdominalis.

\title{
Explanation of Plates
}

\section{Plate VII.}

Fig. 1. Nicocles lomo sp. nov.

$a$. Antenna, greatly enlarged.

Fig. 2. Lestomyia redlandoe sp. nov.

a. Antenna, greatly enlarged.

\section{Plate VIII.}

Fig. 3. Lasiopogon drabicolum sp. nov.

$a$. Antenna, greatly enlarged.

Fig. 4. Cophura highlandica sp. nov.

\section{Plate IX.}

Fig. 5. Metapogon pictum sp. nov.

a. Head from side.

$b$. Outline of head from front.

Fig. 6. Lestomyia montis sp. nov.

a. Antenna, greatly enlarged.

\section{PLASTER-CASTING INSECT BURROWS.}

\author{
By R. P. Dow, \\ New York City.
}

During my visits to J. Turner Brakeley, the hermit naturalist of Lahaway, N. J., we devoted much time to making plaster casts of burrows in the soil. Occasionally we tried the hole made by a snake, rat or even chipmunk, but for the most part our efforts were entomological. Great bare patches of sandy ground were, par excellence, insect homes. One hillside patch was the favorite haunt of Myrmeleon larvæ, their traps pitting every square foot of surface. The larvæ of Cicindela avoided such places, perhaps lest overpopulation should spell starvation. They had haunts of their own, some species, notably C. lepida, preferring absolutely 
bare white sand, others, modesta consentanea, generosa, liking a surface sparsely covered with pine needles with slight growth of weedy grass. Almost all species are fond of the ruts in the woodpaths seldom rendered dangerous by passing tires or human feet. The "pepo" spiders were omnipresent, although seeking a space perfectly clear for at least a few inches adjacent to the burrow mouth. The various species of wild bees have a habitat of their own, on sloping land where the trees are sparse enough to admit sunlight and where the clay subsoil is confined many feet below the surface. Ant burrows were, of course, abundant and ubiquitous. Here and there, too, were many burrows of whose architects we never learned.

All methods of studying insects underground have their limitations, even their failures. On the whole, as satisfactory as any, has been the plaster cast. This was Mr. Brakeley's own invention and a matter of great pride to him. It has already (a score of years ago) been described in scientific literature, but is seldom practised, for although collectors are numerous, observers of nature are still rare. Besides, it sometimes calls for much labor and always for great delicacy of touch. The Cicindela burrow, from six to fourteen inches deep, presents no great task, but that of a Colletes bee, extending sometimes seven feet vertically, is a different matter. The late John B. Smith, for twenty-eight years a welcome and frequent visitor at Lahaway, dug out one or two, but for the most part he poured the plaster and sat smoking a cigar allowing the hermit to wield the spade until the pit resembled a small cellar. It was easy for me to do the same. In the first place Mr. Brakeley pronounced me an awkward bumpkin almost certain to smash the cast, and secondly he claimed to be fond of the exercise which kept his muscles limber.

The method in brief: equal volumes of water and plaster of Paris are mixed quickly in a pitcher. If salt water were used the plaster would "set" so quickly that it could not be poured. It has been suggested that by mixing a couple of tablespoonfuls of liquid glue with the water setting is retarded and the cast is stronger. Even at best the mixture must be poured quickly with unshaking hand, since it becomes too hard for use in less than twenty seconds. Three ounces of mixture will fill any Cicindela burrow. About four and one-half are needed for a "pepo" spider. A Colletes requires seven to nine ounces, the pouring of which 
renders the delay of a second dangerous. If one would like to essay a nest of Formica exsectoides from which, say, three bushels of earth had been thrown out, it would take about ninety-six pounds of plaster solution. This is only practicable by mixing, say, eight ounces at a time and making nearly 200 separate pourings, trying each surface hole before pouring the second installment into the same hole. Thus the lowest levels would be filled and later superpositions become easier. The smaller species of ants can often be treated with a few ounces of plaster, but great care must be taken as most of the galleries are nearly horizontal and the entrance so small that the thread-like stream of plaster lacks the weight to force its way through the laterals. In such cases, and in Cicindela burrows built on a sidehill with horizontal entrance, I have succeeded by taking a wide bottomed paper cone into which a considerable weight of plaster furnished by gravity the force necessary to fill not only laterals on the level but even those which rise several inches.

A great obstacle to success is the resistance of the inhabitant. The body of the "pepo" is almost as large as the neck of its hole (Fig. 11). ${ }^{1}$ When she perceives the stream of plaster coming she opposes her body to it, with the result that the plaster falls on all sides of her insufficiently liquid to rejoin, and thus the cast is almost always hollow, the victim either escaping or being buried near the neck. If there are young in the burrow she resists to the death. Everything in the burrow is caught in the surface of the plaster. The Cicindela larva opposes its chitinized head to the plaster flow in the same manner and often blocks it completely. In such case the luckless one is hauled up with head imbedded in solidified plaster, to be killed as an act of mercy. If the cast be wholly successful the larva is either forced to the bottom or remains imbedded in it, leaving the cast hollow beneath it.

Often there adheres to the bottom an oval film, not of spun silk nor discarded larval skin. I presume that this is the covering of a pupa of a parasite and that the pupa of the beetle is naked. Mr. Brakeley bred out some parasites, but he sent them, as was his custom, to some scientist and never got back either specimen or name.

Ants do not make the same sort of resistance. Those which do not escape via some other gallery are imbedded in the surface of

${ }^{1}$ All figures are reduced about one third from natural size. 
the plaster with the eggs, grubs, inquilines and every other inhabitant of the nest. They do, however, gather to protect their queens. I have had nests in which queens were caught by the legs and their protectors kept the plaster from covering them. One such lay on my table for a month. Three surviving ants watched over the queen. I furnished food, so that it is probable that they died of old age, rather than starvation.

So much for the easy part, the pouring of the plaster. The novice, too eager to see his results, digs out the cast on the same day, and the wet plaster, still soft, breaks into a hundred pieces. The best way is to make a cast one week end and dig it out the next. Then you have a chance of getting your cast home.

The digging out requires first that a pit be dug alongside not closer than a foot from the vertical, otherwise the spade may strike the tube. This must be deeper than the estimated depth of the whole tube. An ordinary table knife is the next useful implement. Beginning near the bottom the earth must be dissected away, never roughly or hastily, until the plaster tube is detected. Then a still more delicate knife, or spatula, comes into play. The cast must be wholly freed from the bottom first. If near the top, it will surely fall and break. It is a veritable triumph, causing feelings of hilarious elation, to detect the bottom of a bee burrow and progress until all the clay cells containing the grubs, etc., are fully exposed for half their circumference, and then to uncover the tube, about as thick as a lead pencil and extending, may be, five feet without a branch.

There are no especial seasons for making casts. Burrows are clean mouthed and inhabited from early spring until frost time. It is well, however, to choose burrows which show fresh earth around them. After every rain the occupant has to clean house, and the result invariably shows. Surface sand burns white. At a depth of six inches it is almost always colored yellow by iron oxides. The yellow upcasts betray the situation. The bees are especially vexatious. The female often digs a score of holes before adopting one permanently. I have watched a species of gray bee flitting and lighting for hours. She kicked away soil with hind legs with marvelous rapidity, until in fewer than twenty seconds she would be entirely out of sight. If she encountered a pebble she abandoned the hole, or backed out with pebble held by her 
four hind legs, locomoting with the forward pair. She abandoned hole after hole without visible reason. I once filled sixty such burrows without finding one unabandoned. In this case, as the soil was "made" on the seashore by a sand pump, fresh diggings could not be distinguished.

But, for the present; the matter under consideration relates to Cicindela. The illustrations are crudely drawn from actual casts and the identification of species is made from a similar burrow. This is accomplished by putting a wire net over a burrow during pupal season and catching a freshly hatched adult. The task is not easy in case of the supposedly two brooded species. Many, perhaps most, of these live in the larval state into the second year. Of $C$. lepida I can be certain, for I have watched them in a territory of my own discovery on Brakeley land. Mr. Brakeley had previously taken a few specimens over his 335 acres, and I found the colony, clustering around a spot where there were the remains of an Indian campfire on the dunes, and where I found also beautiful arrow and spear heads. C. lepida and the Delaware Indians camped on the same spot. On July 18, 1915, I saw C. lepida scampering by the thousands; their flight is very short, never over six feet, and they run more quickly than dorsalis. As I had no net (the mercury was $90^{\circ}$ in the shade, and on this hot sand dune $130^{\circ}$ or over) I took only a dozen with bare hand, stalking them on knees and the other hand. Their larval burrows could be seen by the thousands. The description given by $\mathrm{Mr}$. Wenzel, quoted from J. B. Smith's list of the Insects of New Jersey, is correct so far as it goes. But the insect is scarce at Jamesburg and only burrows under grass tufts were found. The species does not choose such sites rather than another. The burrows were at least one per yard of dune and the number under grass tufts about in ratio with the area of grass tuft vs. clear open sand. The entrance hole has a characteristic shape, which, once seen, can never be mistaken.

Fig. 2 shows the shape of the surface aspect of most Cicindela burrows. Fig. 4 shows C. lepida. Fig. 5 is a cast of C. lepida burrow.

All Cicindela burrows that I have seen agree in general plan. They consist of a pit from which a long, slender tube extends, at first, not far from horizontal for a distance slightly shorter than the 
body of the larva. The insect lies habitually with its head at the opening of the tube and presumably with the abdominal hump catching at the corner. Its sensory organs are so keen that it retires into its tube before an observer can look in. After many minutes of quiet watching one may see it no longer alarmed, and back in place. The burrows exhibit three general types, each species never departing from its own. Fig. 1 is that of C. punctulata, the simple burrow, depending on its depth for victims. Apparently the larva has to leave its tube to devour its prey. Fig. 2 is the surface aspect, but applies equally to most other species, and is given here merely for contrast to the aspect of $C$. lepida. Fig. 10 is an enigma to me. It looks like a $C$. punctulata burrow without trace of a tube. I have burrows of young larvæ, in which the tube is scarcely $3-32$ if an inch in diameter. It may not be argued that the burrow, Fig. 10, indicates that the trap is dug before the tube. On the contrary, the tube is dug and enlarged as the larva grows.

Figs. 3 and 8 are of the no-trap plan. One is typical of what I assume to be $C$. modesta. The other has a trap slanting upward, useless as a prey-catcher. I assume that this was made by the enforced removal of a pebble. Fig. 6 is the double-trap type, which I know to be characteristic of $C$. tranquebarica. Here the victim has the choice of two shallow pits to flounder in while the tiger leans out of its tube devouringly. The fourth type is the singletrap, the pit generally of some length and slanting not far from the horizontal. Fig. 5 is the typical C. lepida burrow on open sand. An insect having fallen therein would naturally run for safety into the cul de sac. Fig. 9 is a C. lepida burrow under a grass tuft. The cul de sac meets requirements of environment, but is much broader. Fig. 7 is an aberration or some species not identified. It was larger than and its surface different from that of $C$. lepida. I suspected $C$. consentanea from environment, but lack evidence. The $C$. sexguttata tribe does not generally burrow in open spaces.

Two common species, $C$. rugifrons and $C$. dorsalis, are still to be plaster-casted. I can safely predict that their burrows will be found to have specific distinctive characters. In fact, I may predict that every species of Cicindela can be differentiated by its larval burrow. 
Vol. XXIII, Plate X.

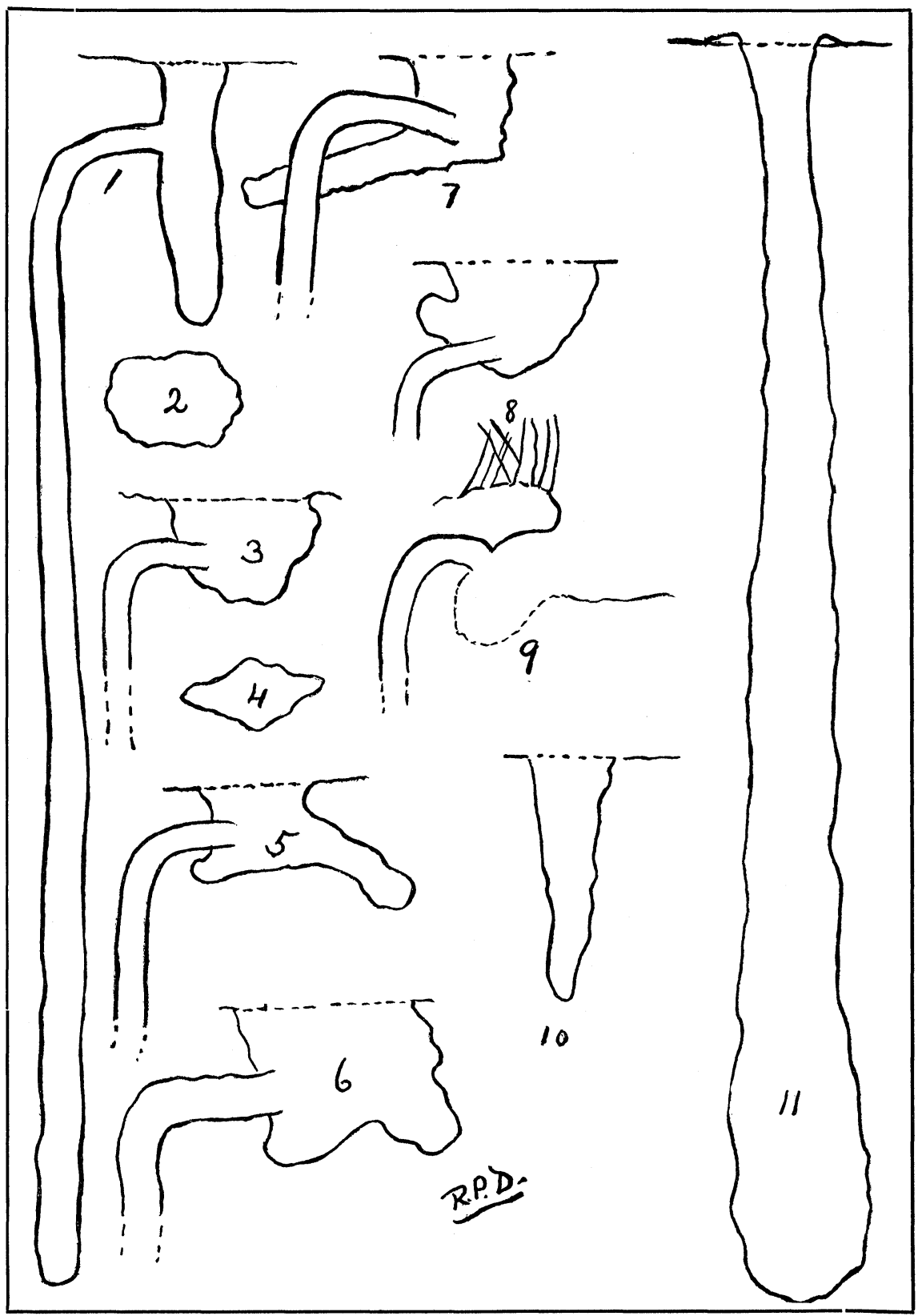

Dow-Plaster Casts of Insect Burrows. 

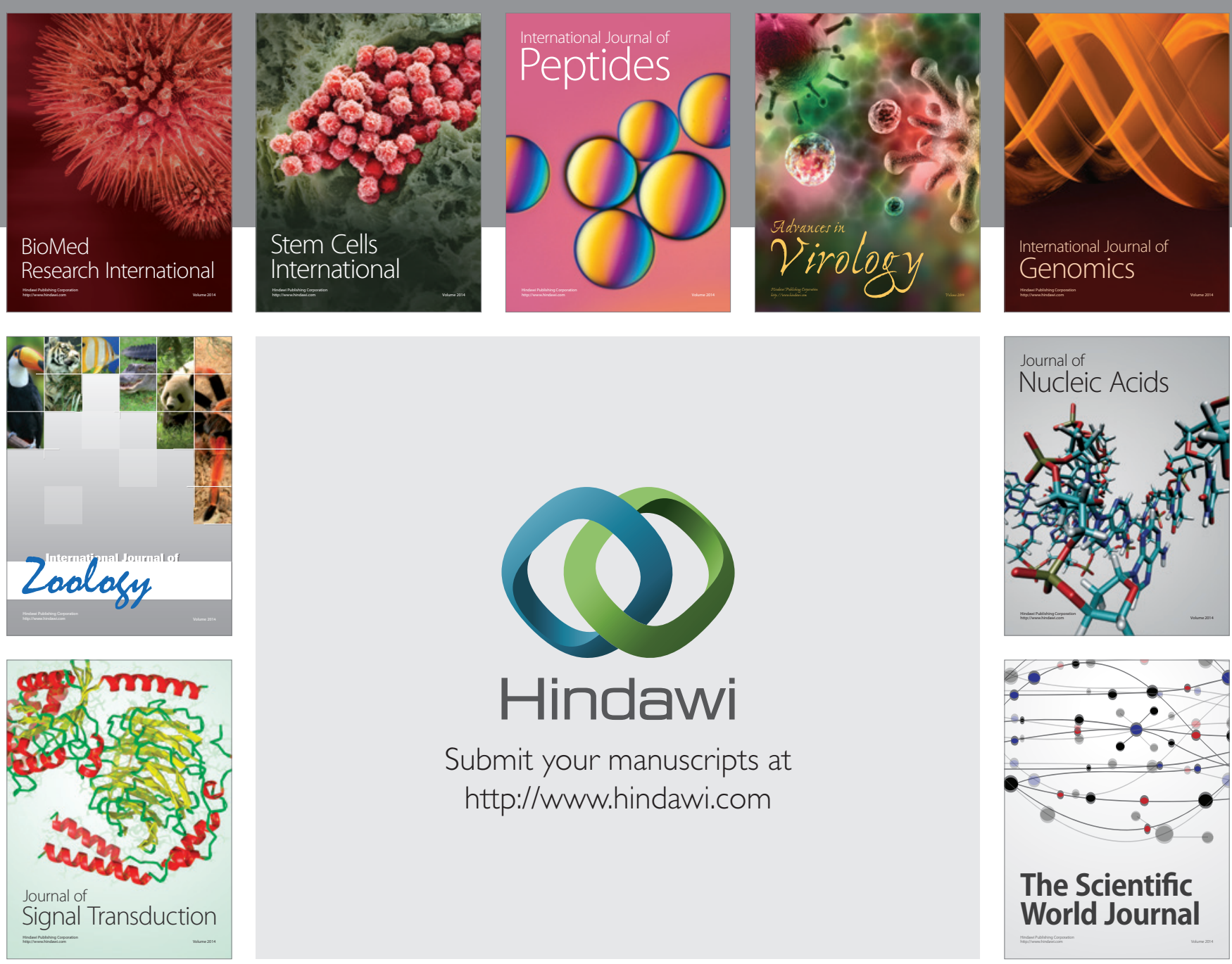

Submit your manuscripts at

http://www.hindawi.com
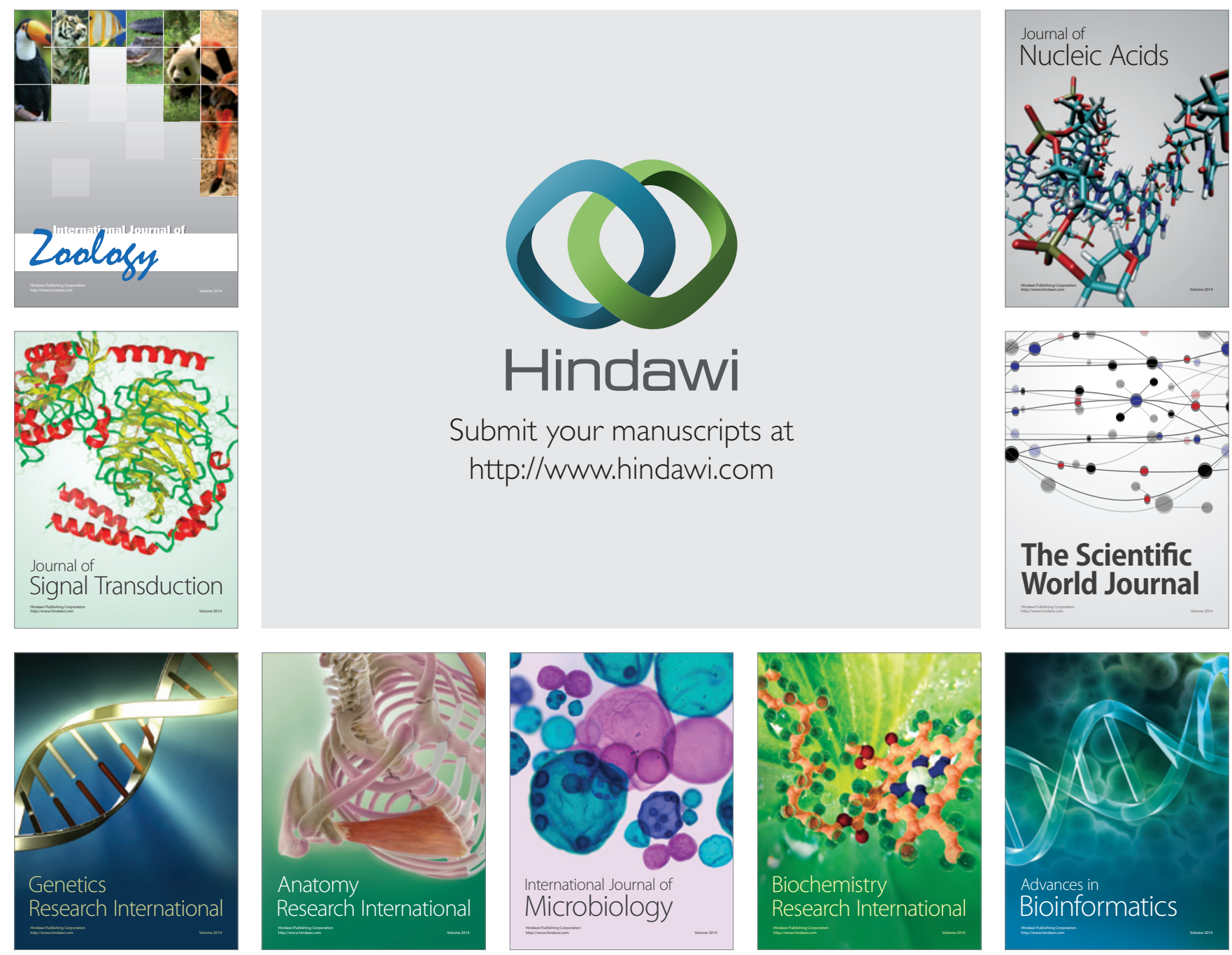

The Scientific World Journal
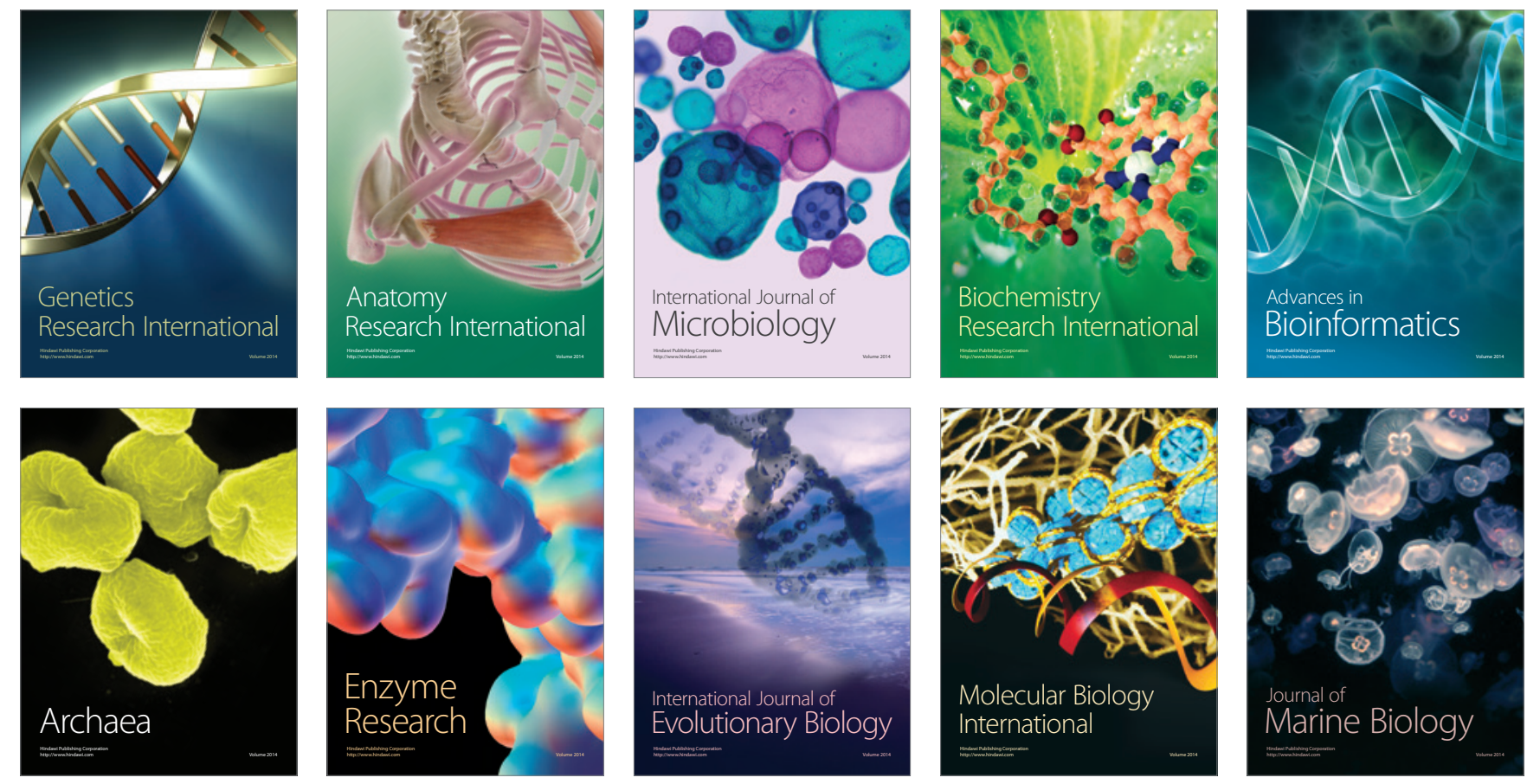